\title{
Effect of the replacement of dietary vegetable oils with a low dose of extravirgin olive oil in the Mediterranean Diet on cognitive functions in the elderly
}

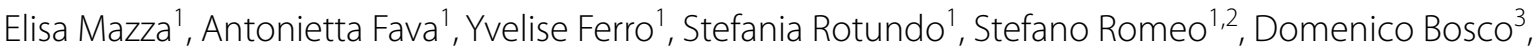 \\ Arturo Pujia ${ }^{1}$ and Tiziana Montalcini ${ }^{4^{*}}$
}

\begin{abstract}
Background: Numerous studies have investigated the role of the monounsaturated fatty acid and other dietary factors in the prevention of cognitive decline but the short-term effect of a low dose of extravirgin olive oil on cognitive performances in the elderly have not still been investigated. Our aim was to investigate whether the replacement of all vegetable oils with a lower amount of extravirgin olive oil, in the contest of a Mediterranean Diet, would improve cognitive performances, among elderly Italian individuals.

Methods: 180 elderly individuals were randomly assigned to these treatment groups for 1 year: (1) MedDiet plus extravirgin OO, 20-30 g/day; (2) control MedDiet. The cognitive sub-test of ADAScale was used to detect cognitive decline progression over 12 months.

Results: ADAS-cog score variation after 1 year, adjusted for food groups which were different between groups, was $-1.6 \pm 0.4$ and $-3.0 \pm 0.4$ in the MedDiet and MedDiet plus extravirgin $\bigcirc \bigcirc$ groups, respectively $(p=0.024)$. Extravirgin $\bigcirc O$ intake was $30 \mathrm{~g} \pm 12$ and $26 \mathrm{~g} \pm 6$ in the MedDiet and MedDiet plus extravirgin OO groups, respectively $(p=0.044)$.
\end{abstract}

Conclusions: We demonstrated the higher short-term improvement of cognitive functions scores in individuals of the MedDiet plus low dose of extravirgin olive oil rather than MedDiet alone. Extravirgin olive oil is the best quality oil and may have a neuroprotective effect.

Keywords: Cognitive functions, Elderly, Mediterranean Diet, Extravirgin olive oil

\section{Background}

Individuals with cognitive impairments and dementia increase in prevalence exponentially with age, with trends worldwide likely to worsen in ensuing decades [1]. These clinical conditions are associated with high overall costs representing a severe burden to society which need to plan wisely to allocate appropriate resources to meet the demands of the disease. Thus, all non-pharmacologic

\footnotetext{
*Correspondence: tmontalcini@unicz.it

${ }^{4}$ Department of Clinical and Experimental Medicine, Nutrition Unit,

University Magna Grecia, Viale S. Venuta, 88100 Catanzaro, Italy

Full list of author information is available at the end of the article
}

measures are also important. Several observational studies and randomized controlled trials have shown the protective role of the Mediterranean Diet (MeDiet) against cognitive decline and in decreasing the risk of developing Alzheimer disease (AD) [2-7].

MeDiet can improve cognitive performances in the elderly [2] and the beneficial effects have been attributed to its high monounsaturated fatty acid (MUFA) content [6] which makes MedDiet a healthy dietary pattern regardless of its high fat content [8]. However, the main concern in the elderly is the change in healthy dietary habits, a reduced interest in food intake and calorie 
counting, especially in individuals with some degree of cognitive decline [9].

A research suggests that food quality, but not quantity, is a key determinant in order to achieve and maintain a healthy status [10]. Furthermore, there are uncertainties on the notion that increasing MUFA intake per se is effective in improving cognitive functions [11]. In this study, we hypothesized that a change in the quality of vegetable oils would improve the cognitive performances in the elderly better than the quantity. A specific associations between extravirgin olive oil (OO) consumption, and cognitive functions have not still been formally examined, especially at low doses and in the short term.

Thus, our aim was to investigate whether the replacement of all vegetable oils with a lower amount of extravirgin $\mathrm{OO}$, in the contest of a MedDiet, would improve cognitive performances, in the short-term, better than a control MedDiet in a population of elderly individuals.

\section{Methods}

This study included participants recruited into the study entitled: Effect of the MedDiet on cognitive function in the elderly" carried-out between February 2013 to August 2016, funded by Italian Ministry of Health and whose protocol was approved by the local ethics committee at the "Mater Domini" University Hospital in Catanzaro, Italy (projects codes 2011.48).

The participants were from a Mediterranean area (Calabria region, southern Italy) and were invited to participate in the study by newspapers advertisements. All subjects were white, community-dwelling individuals aged $\geq 65$ years and had an MMSE score greater than 20 [12]. Participants were literate and were not suffering from any debilitating diseases (like stage $2-5$ chronic kidney disease, end stage liver failure, cancer, congestive heart failure) as ascertained from their medical history, a physical and neurological examination and laboratory tests. They had no previous history of cardiovascular disease (CVD) or thyroid dysfunction or excessive alcohol consumption and did not take any dietary supplements, psychotropic drugs. All participants underwent a neuropsychological assessment conducted by an expert neurologist using a medical assessment and the following neuropsychological tests: the Mini Mental State Examination (MMSE) [13-16] and the Alzheimer's Disease Assessment Scale-Cognitive sub-scale (ADAS-cog) [17-19].

Then 180 participants were randomly assigned to one of the two dietary treatment groups for 1 year (allocation ratio 1:2): (1) a MedDiet in which all vegetable oils (including olive oil, high-oleic safflower oil, high-oleic sunflower oil, canola oil and hydrogenated vegetable oils) were substituted by extravirgin $\mathrm{OO}$ at dose of $20-30 \mathrm{~g}$ per day, (2) a control MedDiet alone (Fig. 1).

To improve adherence, in the MedDiet plus extravirgin $\mathrm{OO}$ group, extravirgin $\mathrm{OO}$ was given for free to participants and provided every 3 months by local oils producers $5 \mathrm{~L}$ of extravirgin $\mathrm{OO}$ for 3 months by Opipari and Torchia Companies, Calabria; extravirgin OO main characteristics: acidity $<0.8 \%$, polyphenol content $280 \mathrm{ppm}$ ).

Participants received intensive oral and written recommendations to increase adherence to the MedDiet, reduce all types of fat but energy restriction was not advised for any of the intervention groups. We performed a longitudinal evaluation lasting 12 months with the ADAS-Cog as the main outcome [18].

The investigation conforms to the principles outlined in the Declaration of Helsinki [20]. Written informed consent was obtained from participants.

\section{Neuropsychological assessment}

The neuropsychological assessments were conducted alongside the medical visit and the use of the MMSE and ADAS-cog. MMSE is a global test of cognitive function with components of orientation, attention, calculation, language and recall [13]. A score of 20 or below is indicative of cognitive impairment. A validated Italian version was used [16]. The ADAS-cog is a psychometric scale, measuring memory disturbances, language, praxis, attention and other cognitive abilities [17]. The range of scores is from 0 to 70 and the scale of the ADAS-cog is reversed, where 0 represents no errors and 70 represents errors on all items $[18,19]$.

Furthermore, we used validated scales to assess behavioural and psychological symptoms and the eventual reduced everyday functional ability which can frequently accompany cognitive decline, such as: Beck Depression Inventory-II (BDI-II), Verbal Fluency (VF), Activities of Daily Living (ADL) and Instrumental Activities of Daily Living (IADL) scales [21-27].

To reduce the potential for practice effects during subsequent visits, different word lists in the neuropsychological tests were used. In addition, the investigators performing the cognitive tests were blinded to the patients' clinical data and randomization.

\section{Anthropometric measurements and cardiovascular risk factors assessment}

Body weight was measured before breakfast after a $12 \mathrm{~h}$ overnight fast with the subjects lightly dressed, subtracting the weight of clothes. Body weight was measured on a calibrated digital scale (model Tanita BC-418MA) accurate to $0.1 \mathrm{~kg}$, and standing height was measured with a wall-mounted stadiometer [28]. BMI was calculated with 


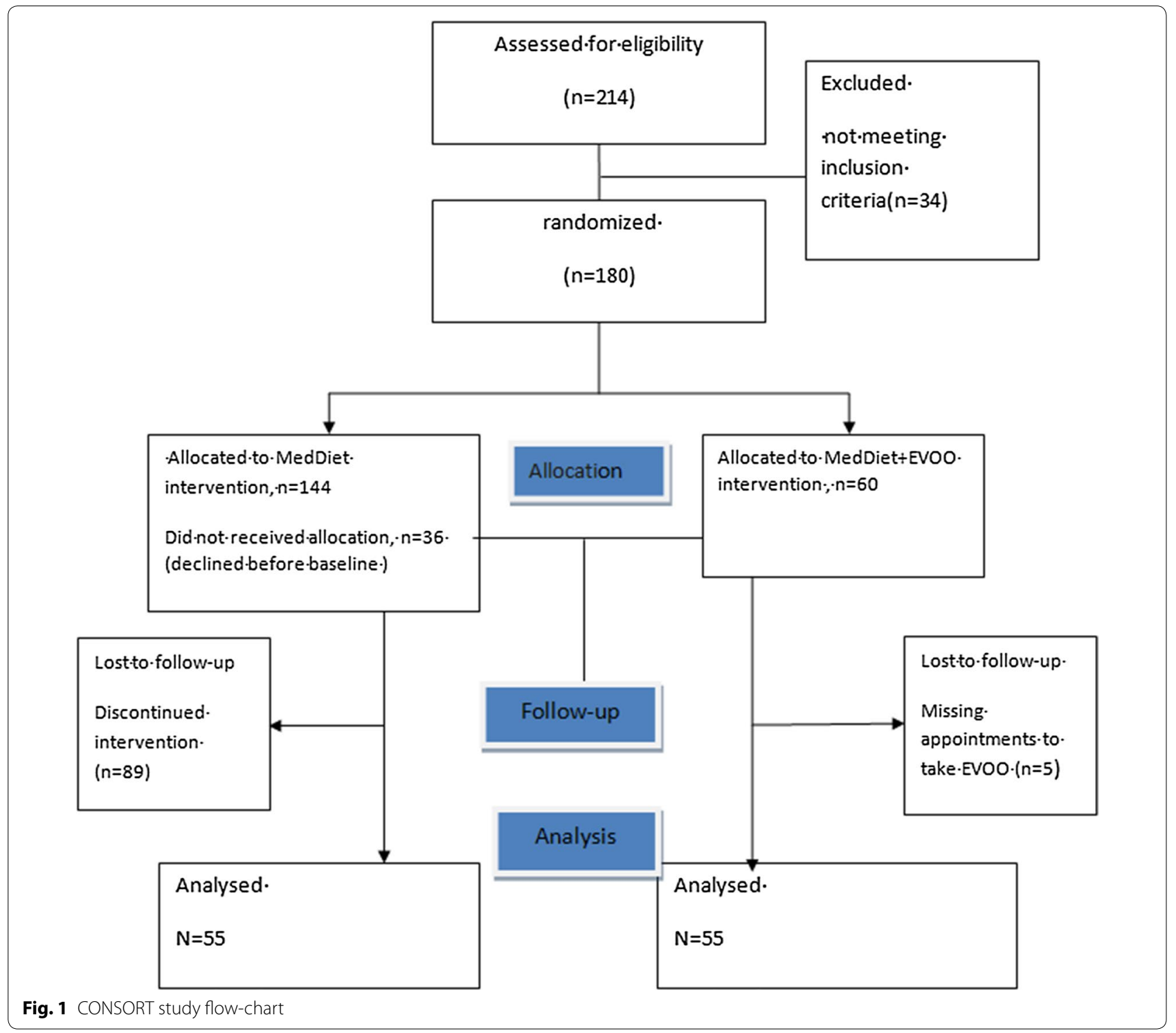

the following equation: weight $(\mathrm{kg}) /$ height $(\mathrm{m})^{2}$. Obesity was defined by the presence of a body mass index $(\mathrm{BMI}) \geq 30 \mathrm{~kg} / \mathrm{m}^{2}$. Waist circumferences and hip circumferences (WC and $\mathrm{HC}$ ) were measured with a nonstretchable tape over the unclothed abdomen at the narrowest point between costal margin and iliac crest and over light clothing at the level of the widest diameter around the buttocks, respectively, as described in the past [28].

We assessed the presence of the classical cardiovascular (CV) risk factors, such as hyperlipidemia, hypertension, diabetes and smoking, from clinical records and patient interview [12, 28]. Blood pressure was determined at the time of the two visits.
Dietary intake and cardiovascular risk factors assessment

Dietary intake data were assessed by a 24-h recall and a 7-day food record [12, 29], and calculated using nutritional software MetaDieta 3.0.1 (Metedasrl, San Benedetto del Tronto, Italy). Precisely, the 24 -h recall was performed via a face-to-face interview with a dietitian who used images associated with a comprehensive food list. The recall required $15-20 \mathrm{~min}$ to complete for each participant. The patients were also asked to report any ingredients, food and food waste in a food diary for a 7-day period. Each patient was trained by a skilled dietitian before starting the study. The dietitian showed how various foods should be recorded. The portion sizes used 
were based on the typical or natural portion consumed (e.g., a slice of bread, one egg). When a typical portion size was not obvious, a commonly-used portion size was selected (e.g., one cup). The nutrient database used to calculate nutrient intake was derived primarily from INRAN (National Institute of Food Research) 2000 and IEO (European Institute of Oncology) 2008 [12, 29]. This database includes over 5000 foods and brand name products, and is updated annually. Briefly, dietary intake data were entered directly into the software MetaDieta. The software searches for foods and brand products by name. The coding of foods and their variable ingredients occurs as data are entered, with the simultaneous immediate calculation of nutrients. Nutrient values and other food components were generated from the database together with food group assignments. The adherence to MedDiet was assessed at enrollment using the Mediterranean Diet Score (MDS) [4]. Total score ranges from 0 (minimum adherence) to 55 (maximum adherence). A score from 25 to 55 indicates a moderate-high adherence to MedDiet. Furthermore, we assessed the Mediterranean Adequacy Index (MAI) at enrollment and after 1 year [30]. Three levels of adherence were considered: $\leq 2$ low score; $\geq 4$ high score and $2 \leq \mathrm{MAI} \leq 4$ intermediate score.

\section{Biochemical evaluation}

Venous blood was collected after fasting overnight into vacutainer tubes (Becton \& Dickinson, Plymouth, England) and centrifuged within $4 \mathrm{~h}$. Serum glucose, total cholesterol, high density lipoprotein (HDL)-cholesterol, triglycerides and creatinine were measured with Enzymatic colorimetric test. Low-density lipoprotein (LDL) cholesterol level was calculated by the Friedewald formula [31]. Quality control was assessed daily for all determinations.

\section{Data analysis}

Data are reported as mean \pm SD. Since an effect size of ADAS-Cog change (ES = mean ADAS-cog difference/ baseline SD) of 0.8 has been considered as a large clinically relevant change [32], with $80 \%$ power on a twosided level of significance, a minimum of 25 subjects for each group are required.

A Chi square test was performed to analyze the difference in prevalence between groups and an independent unpaired samples t test was used to compare the means of the two groups at baseline and after 1 year. Changes in MMSE and ADAS cog score from baseline to followup (within group variation) were compared using paired Student's $t$ test (two tailed). The general linear model (GLM) was used to adjust the ADAS-cog variation for all variables significantly different between groups at baseline and after 1 year.
Significant differences were assumed to be present at $p<0.05$ (two-tailed). All comparisons were performed using SPSS 17.0 for Windows (IBM Corporation, New York, NY, United States).

\section{Results}

A total of 110 individuals completed the study (55 participants/group, Fig. 1). Table 1 shows the baseline characteristics of the study population according with the randomization. The two groups were comparable for age, gender, BMI and calories intake. The mean age was $70 \pm 4$ years, the MMSE score was $24 \pm 1$ in both groups $(\mathrm{p}=0.63$ and 0.72 respectively) and ADAS-cog score was $14 \pm 4$ and $15 \pm 5$ in the MedDiet and MedDiet plus extravirgin $\mathrm{OO}$ groups, respectively $(\mathrm{p}=0.14)$. Furthermore, all other baseline characteristics were not significantly different between groups.

The baseline participants' nutritional intake is showed in Table 2. Energy intake was not significantly different between groups. Only alcohol and cheese consumption were significantly different between groups (alcohol: $9 g \pm 12$ and $5 g \pm 8$ in the MedDiet and MedDiet plus extravirgin $\mathrm{OO}$ groups, respectively, $\mathrm{p}=0.037$; cheese: $48 \mathrm{~g} \pm 39$ and $66 \mathrm{~g} \pm 50$ in the MedDiet and MedDiet plus extravirgin $\mathrm{OO}$ groups, respectively $\mathrm{p}=0.038$ respectively).

\section{Characteristics of the study population and neuropsychological score after 1 year}

Clinical characteristics and dietary intake were not significantly different between groups after 1 year, except for extravirgin $\mathrm{OO}(30 \mathrm{~g} \pm 12$ and $26 \mathrm{~g} \pm 6$ in the MedDiet and MedDiet plus extravirgin OO groups, respectively, $\mathrm{p}=0.044$ ), and carbohydrates, fruit and milk consumption (Table 3).

ADAS-cog scores improved at the second time point in the participants taking extravirgin $\mathrm{OO}$ as well as in participants in the MedDiet group (Table 4), but ADAS-cog change was significantly different between groups (ADAScog change of $-1.6 \pm 2$ and $-3.0 \pm 3$ in the MedDiet and MedDiet plus extravirgin OO groups, respectively, $\mathrm{p}=0.018$; Table 5). In particular, ADAS-cog score variation, adjusted for alcohol and cheese (baseline intake) and carbohydrates, fruit and milk (intake after 1 year) was $-1.6 \pm 0.4$ and $-3.0 \pm 0.4$ in the MedDiet and MedDiet plus extravirgin OO groups, respectively, $\mathrm{p}=0.024$, Table 5). All other neuropsychological scores were not significantly different between groups after 1 year.

\section{Discussion}

The findings of the present study show a higher reduction of ADAS-cog scores (improved test) after 1 year in the elderly of the MedDiet plus low dose of extravirgin 
Table 1 Baseline participant's demographic, anthropometric and clinical characteristics according to randomization

\begin{tabular}{|c|c|c|c|}
\hline Variables & $\begin{array}{l}\text { MeDiet } \\
(\mathrm{N}=55)\end{array}$ & $\begin{array}{l}\text { MeDiet plus EVOO } \\
(\mathrm{N}=55)\end{array}$ & $p$ value \\
\hline Age (years) & $70(4)$ & $70(4)$ & 0.63 \\
\hline Weight (Kg) & $71(11)$ & $72(14)$ & 0.68 \\
\hline $\mathrm{BMI}\left(\mathrm{Kg} / \mathrm{m}^{2}\right)$ & $28.0(5)$ & $28.8(4)$ & 0.35 \\
\hline WC (cm) & $97(11)$ & $96(13)$ & 0.97 \\
\hline $\mathrm{SBP}(\mathrm{mmHg})$ & $128(15)$ & $132(11)$ & 0.16 \\
\hline $\mathrm{DBP}(\mathrm{mmHg})$ & $78(8)$ & $80(9)$ & 0.27 \\
\hline Glucose (mg/dL) & $104(34)$ & $101(21)$ & 0.60 \\
\hline Creatinine (mg/dL) & $0.86(0.2)$ & $0.81(0.2)$ & 0.21 \\
\hline $\begin{array}{l}\text { Total cholesterol } \\
(\mathrm{mg} / \mathrm{dL})\end{array}$ & $200(44)$ & $194(40)$ & 0.46 \\
\hline $\begin{array}{l}\text { HDL cholesterol } \\
\text { (mg/dL) }\end{array}$ & $54(15)$ & $59(15)$ & 0.14 \\
\hline $\begin{array}{l}\text { LDL cholesterol (mg/ } \\
\text { dL) }\end{array}$ & $128(41)$ & $124(34)$ & 0.53 \\
\hline Triglycerides (mg/dL) & $123(61)$ & $108(55)$ & 0.18 \\
\hline \multicolumn{4}{|c|}{ Neuropsychological assessment } \\
\hline $\begin{array}{l}\text { Education level } \\
\text { (years) }\end{array}$ & $11(5)$ & $11(5)$ & 0.56 \\
\hline MMSE & $24.6(1.3)$ & $24.5(1.5)$ & 0.72 \\
\hline ADAS-Cog & $14.0(4.5)$ & $15.3(5.2)$ & 0.14 \\
\hline$A D L$ & $6.0(0.1)$ & $6.0(0.1)$ & 0.43 \\
\hline IADL & $8.0(0.1)$ & $8.0(0.2)$ & 0.15 \\
\hline VF & $25(6)$ & $23(7)$ & 0.15 \\
\hline BDI-III & $11(7)$ & $13(8)$ & 0.30 \\
\hline \multicolumn{4}{|l|}{ Prevalence } \\
\hline Smokers (\%) & 52 & 36 & 0.36 \\
\hline Hyperlipidemia (\%) & 48 & 55 & 0.56 \\
\hline $\begin{array}{l}\text { Lipid-lowering } \\
\text { agents (\%) }\end{array}$ & 45 & 50 & 0.50 \\
\hline Hypertension (\%) & 52 & 51 & 0.90 \\
\hline $\begin{array}{l}\text { Antihypertensive } \\
\text { agents (\%) }\end{array}$ & 50 & 49 & 0.60 \\
\hline $\begin{array}{l}\text { Diabetes/carbohy- } \\
\text { drate intolerance } \\
(\%)\end{array}$ & 54 & 41 & 0.34 \\
\hline $\begin{array}{l}\text { Oral hypoglycemic } \\
\text { agents (\%) }\end{array}$ & 51 & 40 & 0.40 \\
\hline
\end{tabular}

EVOO extra virgin olive oil, $B M I$ body mass index, WC waist circumference, $S B P$ systolic blood pressure, $D B P$ diastolic blood pressure, $H D L$ high density lipoprotein, $L D L$ low density lipoprotein, $M M S E$ mini mental state examination, $A D A S$-Cog Alzheimer's disease assessment scale-cognitive sub-scale, $A D L$ activities of daily living, IADL instrumental activities of daily living, $V F$ verbal fluency, BDI-III Beck depression inventory

OO group than that observed with a MedDiet alone $(-3.0 \pm 0.4$ Vs. $-1.6 \pm 0.4$ respectively; Table 4$)$. This result suggests that, in the short term and despite a low dose, extravirgin OO could be involved in improving the ADAS-cog scores whereas a MedDiet alone slightly preserve cognitive functions. In this study, the two groups
Table 2 Nutrients and food groups assessment according to extra virgin olive oil intake-baseline

\begin{tabular}{|c|c|c|c|}
\hline Nutrients intake & $\begin{array}{l}\text { Without EVOO } \\
(\mathrm{N}=55)\end{array}$ & $\begin{array}{l}\text { With EVOO } \\
(\mathrm{N}=55)\end{array}$ & $p$ value \\
\hline Calories (Kcal) & $1880(452)$ & $1814(376)$ & 0.40 \\
\hline MAl & $2.92(1)$ & $2.83(1)$ & 0.67 \\
\hline MDS & $33(3)$ & $33(3)$ & 0.15 \\
\hline Carbohydrates (\%) & $46(6)$ & $47(7)$ & 0.49 \\
\hline Proteins (\%) & $17(2)$ & $17(3)$ & 0.54 \\
\hline Fats (\%) & $37(6)$ & $37(7)$ & 0.70 \\
\hline Carbohydrates (g) & 209 (59) & $207(49)$ & 0.81 \\
\hline Proteins (g) & $78(20)$ & $75(23)$ & 0.55 \\
\hline Fats (g) & $75(20)$ & $73(23)$ & 0.63 \\
\hline $\begin{array}{l}\text { Monounsaturated } \\
\text { fatty acids (g) }\end{array}$ & $38(9)$ & $37(12)$ & 0.64 \\
\hline Alcohol (g) & $9(12)$ & $5(8)$ & 0.037 \\
\hline \multicolumn{4}{|l|}{ Food groups intake } \\
\hline Potatoes (g) & $16(19)$ & $20(25)$ & 0.30 \\
\hline Cereals (g) & 205 (88) & $200(82)$ & 0.77 \\
\hline Legumes (g) & $15(13)$ & $25(31)$ & 0.051 \\
\hline Vegetables (g) & $250(133)$ & $290(136)$ & 0.11 \\
\hline Fruit (g) & $333(162)$ & $345(206)$ & 0.73 \\
\hline Fish (g) & $61(45)$ & $73(64)$ & 0.27 \\
\hline Meat (g) & $79(44)$ & $75(48)$ & 0.66 \\
\hline Eggs (g) & $11(10)$ & $15(28)$ & 0.30 \\
\hline Milk (g) & $139(112)$ & $122(108)$ & 0.43 \\
\hline Cheese (g) & $48(39)$ & $66(50)$ & 0.038 \\
\hline $\begin{array}{l}\text { Animal fats/mar- } \\
\text { garines (g) }\end{array}$ & $0.69(2)$ & $1.5(5)$ & 0.29 \\
\hline Cookies (g) & $7.7(16)$ & $9.6(16)$ & 0.53 \\
\hline Cakes/pies (g) & $28(24)$ & $38(30)$ & 0.059 \\
\hline Sugar drinks (g) & $27(89)$ & $10(30)$ & 0.18 \\
\hline Wine (g) & $90(127)$ & 70 (117) & 0.40 \\
\hline EVOO (g) & $33(10)$ & $36(12)$ & 0.20 \\
\hline
\end{tabular}

had a similar calories and food groups intake at baseline as well as at the second time point (Tables 1,2,3), except for alcohol and cheese (at baseline) and carbohydrates, fruit and milk intake (after 1 year). After adjusting the ADAS-cog score variation for these food groups, a higher improvement of ADAS-cog scores was, again, observed in participants of the MedDiet plus low dose of extravirgin OO than in participants at MedDiet alone.

The beneficial effects of the MedDiet on cognitive functions have been attributed to its high MUFA content [6]. However, several evidences raised uncertainty on this association. In the EPIC-Greek cohort, a population of adults aged 60 years old or more evaluated for a period lasting 8 years, MUFA were not associated with MMSE score [11]. A finding from a cross-sectional study reported that an increased consumption of extravirgin 
Table 3 Participant's demographic, anthropometric and clinical characteristics after 1 year according to extra virgin olive oil-intake

\begin{tabular}{|c|c|c|c|}
\hline $\begin{array}{l}\text { Demographic, anthropometric } \\
\text { and clinical characteristics }\end{array}$ & $\begin{array}{l}\text { MeDiet } \\
(\mathrm{N}=55)\end{array}$ & $\begin{array}{l}\text { MeDiet } \\
\text { plus EVOO } \\
(\mathrm{N}=55)\end{array}$ & $p$ value \\
\hline Weight (Kg) & $71(11)$ & $71(14)$ & 0.99 \\
\hline $\mathrm{BMI}\left(\mathrm{Kg} / \mathrm{m}^{2}\right)$ & $27.9(4)$ & $28.7(4)$ & 0.29 \\
\hline WC (cm) & $96(11)$ & $95(12)$ & 0.80 \\
\hline $\mathrm{SBP}(\mathrm{mmHg})$ & $128(12)$ & $131(15)$ & 0.40 \\
\hline $\mathrm{DBP}(\mathrm{mmHg})$ & $80(8)$ & $78(10)$ & 0.34 \\
\hline Glucose (mg/dL) & $103(23)$ & $103(20)$ & 0.92 \\
\hline Creatinine $(\mathrm{mg} / \mathrm{dL})$ & $0.86(0.2)$ & $0.85(0.2)$ & 0.81 \\
\hline Total Cholesterol (mg/dL) & $192(38)$ & $191(36)$ & 0.81 \\
\hline HDL Cholesterol (mg/dL) & $54(14)$ & $60(17)$ & 0.05 \\
\hline LDL Cholesterol (mg/dL) & $119(37)$ & $117(33)$ & 0.74 \\
\hline Triglycerides (mg/dL) & $121(57)$ & $104(38)$ & 0.08 \\
\hline \multicolumn{4}{|l|}{ Nutrients intake } \\
\hline Calories (Kcal) & $1545(386)$ & $1560(292)$ & 0.81 \\
\hline MAI & $3.09(1)$ & $3.22(1)$ & 0.60 \\
\hline$\triangle \mathrm{MAl}$ & $0.02(1)$ & $0.18(1)$ & 0.51 \\
\hline Carbohydrates (\%) & $47(5)$ & $51(6)$ & 0.002 \\
\hline Proteins (\%) & $16(3)$ & $17(3)$ & 0.48 \\
\hline Fats (\%) & $36(6)$ & $33(5)$ & $<0.001$ \\
\hline Carbohydrates (g) & $177(48)$ & $193(42)$ & 0.053 \\
\hline Proteins (g) & $61(18)$ & $63(16)$ & 0.43 \\
\hline Fats (g) & $60(17)$ & $55(12)$ & 0.07 \\
\hline Alcohol (g) & $8(11)$ & $6(8)$ & 0.21 \\
\hline Monounsaturated fatty acids (g) & $31(10)$ & $28(5)$ & 0.025 \\
\hline Oleic acid (g) & $30(9)$ & $27(5)$ & 0.027 \\
\hline \multicolumn{4}{|l|}{ Food groups intake } \\
\hline Potatoes (g) & $25(24)$ & $26(32)$ & 0.73 \\
\hline Cereals (g) & $164(70)$ & $171(55)$ & 0.56 \\
\hline Legumes (g) & $19(19)$ & $26(25)$ & 0.14 \\
\hline Vegetables (g) & $203(295)$ & $229(128)$ & 0.55 \\
\hline Fruit (g) & $269(149)$ & $336(188)$ & 0.041 \\
\hline Fish (g) & $42(32)$ & $47(40)$ & 0.48 \\
\hline Meat (g) & $72(42)$ & $68(45)$ & 0.64 \\
\hline Eggs (g) & $10(11)$ & $9(11)$ & 0.87 \\
\hline Milk (g) & $104(98)$ & $145(114)$ & 0.043 \\
\hline Cheese (g) & $35(29)$ & $35(26)$ & 0.98 \\
\hline Animal fats/margarines (g) & $0.8(3)$ & $0.7(3)$ & 0.78 \\
\hline Cookies (g) & $8(16)$ & $12(17)$ & 0.28 \\
\hline Cakes/pies (g) & $25(18)$ & $20(20)$ & 0.19 \\
\hline Sugar drinks (g) & $4.0(12)$ & $16(53)$ & 0.11 \\
\hline Wine (g) & 74 (109) & $51(78)$ & 0.20 \\
\hline EVOO (g) & $30(12)$ & $26(6)$ & 0.044 \\
\hline
\end{tabular}

EVOO extra virgin olive oil, BMI body mass index, WC waist circumference, SBP systolic blood pressure, DBP diastolic blood pressure, HDL high density lipoprotein, $L D L$ low density lipoprotein
OO were independently related to better cognitive functions [33]. However, a specific associations between extravirgin $\mathrm{OO}$ intake and cognitive functions or dementia in the short term and with low doses have not been examined yet. Several interventions studies suggest a protective role for $\mathrm{OO}$ or extravirgin $\mathrm{OO}$ on brain functions over a long period of time. In this regard, one study carried out in a population of community-dwelling individuals at high vascular risk, demonstrated that a MedDiet supplemented with EVOO (1 L/week) was associated with a better global cognitive performance after 6.5 years of follow-up compared with a control low-fat diet [2]. In this study, mean MMSE and Clock Drawing Test (CDT) scores were significantly higher for participants allocated to the MedDiet supplemented with extravirgin OO group in comparison with the control group. However ADAScog score was not assessed. In the EPIC-Greek study it has been found that olive oil consumption was weakly positively associated with MMSE score, whereas the association between extravirgin $\mathrm{OO}$ and cognition was no tested [11]. Thus, our investigation is original from the point of view of the duration of the study, quality of the OO (only extravirgin) and doses tested. Our results are consistent with that found by Violi et al. [34] Compared with baseline, in healthy subjects of both gender given a Mediterranean-type lunch containing only $10 \mathrm{mg}$ of extravirgin OO, a significant less increase of blood glucose, LDL-Cholesterol and ox-LDL and a more marked increase of blood insulin were detected [34]. It is well accepted that cardiovascular risk factors such as diabetes, dyslipidemia, hypertension and conditions such as insulin-resistance are associated with the development of cognitive impairments $[35,36]$. Thus, we assumed that extravirgin $\mathrm{OO}$, even at low dose, may positively affect cognitive functions. Furthermore, in November 2004, the US Federal Drug Administration (FDA) allowed a claim on olive oil labels concerning "the benefits on the risk of coronary heart disease of eating about $23 \mathrm{~g}$ of olive oil daily, due to the MUFA in olive oil" [37]. In our study we did find any significant effect on the lipids (data not shown). Nevertheless, since ox-LDL and insulin were not assessed, we cannot rule out these biological effects. In addition, 1 year may be not sufficient to identify cognitive improvements related to reduction of cardiovascular risk factors. We hypothesized that extravirgin OO supplementation rapidly influence cognitive function tests, even at low doses $[2,34-36]$ whereas the MedDiet may prevent cognitive decline over a long period of time and have a beneficial effect during the long prodromal phase of dementia [38]. 
Tables 4 Participant's neuropsychological characteristics after 1 year according to extra virgin olive oil-intake-(within group variation)

\begin{tabular}{|c|c|c|c|c|c|c|c|c|}
\hline \multirow[t]{2}{*}{ Variables } & \multicolumn{4}{|c|}{ Without EVOO } & \multicolumn{4}{|c|}{ With EVOO } \\
\hline & Basal & Follow-up & $\Delta$ & $p$ value $*$ & Basal & Follow-up & $\Delta$ & $p$ value* \\
\hline MMSE & $24.6(1.3)$ & $25.6(1.8)$ & $0.96(1.1)$ & $<0.001$ & $24.5(1.5)$ & $25.9(1.3)$ & $1.3(1.1)$ & $<0.001$ \\
\hline ADAS-Cog & $14.0(4.5)$ & $12.5(3.6)$ & $-1.6(2.4)$ & $<0.001$ & $15.3(5.2)$ & $12.4(4.6)$ & $-3.0(3.3)$ & $<0.001$ \\
\hline EVOO (g) & $33(10)$ & $30(12)$ & $-3.3(13)$ & 0.069 & $36(12)$ & $26(6)$ & $-10(14)$ & $<0.001$ \\
\hline
\end{tabular}

MMSE mini mental state examination, ADAS-Cog Alzheimer's disease assessment scale-cognitive sub-scale, EVOO extra virgin olive oil, $\triangle$ difference

* Paired T test

Table 5 Participant's neuropsychological characteristics after 1 year according to extra virgin olive oil-intake

\begin{tabular}{lccc}
\hline & $\begin{array}{l}\text { MeDiet } \\
(\mathbf{N}=\mathbf{5 5})\end{array}$ & $\begin{array}{l}\text { MeDiet plus EVOO } \\
(\mathbf{N}=\mathbf{5 5})\end{array}$ & $\boldsymbol{p}$ value \\
\hline MMSE & $25.6(1.8)$ & $25.9(1.3)$ & 0.24 \\
$\triangle$ MMSE & $0.96(1.1)$ & $1.3(1.1)$ & 0.08 \\
ADAS-Cog & $12.5(3.6)$ & $12.4(4.6)$ & 0.84 \\
$\triangle$ ADAS-Cog & $-1.6(2.4)$ & $-3.0(3.3)$ & 0.018 \\
$\triangle$ ADAS-Cog & $-1.6(0.4)$ & $-3.0(0.4)$ & 0.024 \\
(adjusted $)$ & & & \\
ADL & $6.0(0.1)$ & $6.0(0.1)$ & 0.50 \\
IADL & $8.0(0.1)$ & $8.0(0.1)$ & 0.32 \\
VF & $25(7)$ & $25(6)$ & 0.78 \\
BDI-III & $11(6)$ & $12(6)$ & 0.56 \\
\hline
\end{tabular}

EVOO extra virgin olive oil, MMSE mini mental state examination, ADAS-Cog Alzheimer's disease assessment scale-cognitive sub-scale, $A D L$ activities of daily living, IADL instrumental activities of daily living, $V F$ verbal fluency, $B D I-I I I$ Beck depression inventory, $\Delta$ difference

a Adjusted mean and standard deviation for alcohol and cheeses (baseline intake) and carbohydrates, fruit and milk (intake after 1 year)

EVOO is the best quality oil, produced by mechanically pressing ripe olives, and retains most of its lipophilic components (including alpha-tocopherol, beta-carotene, and phenolic flavonoid compounds) with strong antioxidant properties [39]. In contrast, common olive oil is a mixture of virgin and refined oil, with fewer antioxidant and anti-inflammatory compounds [38]. An industrial solvent extraction of oil from plants involves the majority of the vegetal oils. Thus, while many vegetable oils may contain MUFAs, the industrialized processing of these oils makes them a less desirable choice for health. For these reasons, it is plausible that a low dose $(\sim 26 \mathrm{~g})$ of extravirgin $\mathrm{OO}$ may have different effects on central nervous system from other vegetal oils, as also suggested by some experimental studies. Compared with virgin $\mathrm{OO}$, refined $\mathrm{OO}$ is less protective on oxidative damage to lipids, free radical generation and inflammatory activity $[40,41]$. Oleuropein is generally the most prominent phenolic compound in olive cultivars, thus, the neuroprotective effects may be mediated by oleuropein [42].
Of course, our study was not designed to investigate which component of $\mathrm{OO}$ (oleic acid or phenols) underlie the association with cognitive functions. Since it has been demonstrated that food quality is a key determinant in order to maintain a healthy status [10], our study suggests that a dietary pattern including extravirgin $\mathrm{OO}$, even at low dose, have a protective action on cognitive functions. Several researches have provided evidence of diet-induced changes in cerebral neurotransmitters [43, 44 ]. Thus, our study may reveal a new approach to prevent the cognitive decline by changing the quality of vegetable oils in the diet.

In this study, as expected, both groups showed an improvement. Our control MedDiet diet improved cognitive functions in line with previous epidemiological and intervention studies [8], possibly through its effect on oxidative stress and inflammation in the brain [32, 39]. However, a higher reduction of ADAS-cog scores was found in the participants of the MedDiet plus extravirgin $\mathrm{OO}$ group than that observed with a MedDiet alone (Table 5).

In our population, no indication about calories restriction was given. However, energy intake decreased by about $300 \mathrm{kcal}$ over 1 year. We hypothesize an age-related reduction in energy intake, that is largely a physiologic effect of healthy aging [9]. Furthermore, physical factors such as poor dentition or age-associated changes in taste and smell may limit the type and quantity of food eaten in older people [9].

In this investigation some weaknesses and strengths must be pointed out. It has been suggested that a mean ADAS-Cog change in individuals judged to have clinically relevant change was over three points with an effect size (ES = mean ADAS-cog difference/baseline SD) of more than 0.5 for a minimal clinically relevant change, with values for those not undergoing a clinically significant change being smaller (0.2-0.4) [32]. Thus, in our study in both groups the change seems to be clinically relevant. However, at present, a cut-off point on the ADAS cog that accurately classifies patients in respect of their clinical response is not universally accepted, especially 
with a dietary intervention. Consequently, caution must be exercised when interpreting our results on the basis of ADAS-cog score change.

To assess how close the food intakes of our population groups were from the Mediterranean Dietary pattern we used MAI, by dividing the sum of the percentage of total energy from typical Mediterranean food groups by the sum of the percentage of total energy from non-typical Mediterranean food groups [30]. The lack of a significant change in the MAI after 1 year was not a surprise since it has been demonstrated that, even though adherence to Mediterranean Diet did not change over time, the consumption of some foods can change toward an healthier food pattern [45]. In addition, our findings are in line with that demonstrated by Fidanza et al. in the elderly [30].

The exclusion of the elderly affected by CVD makes these results not generalizable to a community-dwelling older population but these observations are applicable only to a population with similar characteristics. However, we restricted to individuals without CVD and 1 year of follow-up to reduce the number of potential intermediary events altering the association between the intervention and the studied outcomes. Longer follow-up in the elderly with CVD may be associated with more intermediary events potentially biasing interpretation of the results [46]. In this regard, the rate of drop out during follow-up was of $62 \%$ in the MedDiet group. There are no universally agreed criteria for acceptable follow-up rates in nutritional randomized control trials (RCTs) or cohort studies. However, in RCTs, typically investigating drugs, a cut-off of $80 \%$ is used in Evidence-Based Medicine (EBM) "Levels of Evidence" to separate "high"- and "low"-quality randomised trials $[47,48]$.

They are important points to mention in interpreting the credibility of these findings. Protocol deviations are very common in interventional research. In this study the overall drop-out rate was $53 \%$ and it can have implications on the validity and generalizability of research findings. Of course the method of handling data may lead to different conclusions and it is possible that, in this study, the causal relationship cannot be completely established. However, we explored differences in the characteristics of the participants who completed the study versus those who withdrew (Additional file 1: Table S1) and did not differ significantly, suggesting that the drop-out rate did not impact the final results. We performed a common types of sensitivity analyses to assess the robustness of the results in which participants who violate the protocol (missing appointments; discontinued intervention) were excluded from the analysis. Furthermore, while the overall drop-out rate was $53 \%$, it did not affect power because 25 participants each group were required.
Finally, since it is difficult to disentangle $\mathrm{OO}$ from the other components of the MedDiet, and aimed to improve adherence to the protocol, we designed this randomized study in which, in the MedDiet plus extravirgin OO group, extravirgin $\mathrm{OO}$ was given for free to participants by local oils producers. We believe this is a strength of the study. Further research is needed to establish whether a Mediterranean Diet supplemented with a low dose of extravirgin $\mathrm{OO}$ can prevent dementia.

\section{Conclusion}

In this study, we demonstrated that the higher improvement of cognitive functions scores, in a short-term, was observed in individuals of the MedDiet plus low dose $(\sim 26 \mathrm{~g})$ of extravirgin $\mathrm{OO}$ rather than MedDiet alone. In the elderly, a change in the quality of vegetable oils would improve the cognitive functions better than the quantity. Additional studies are required to confirm this results.

\section{Additional file}

Additional file 1: Table S1. Baseline participant's clinical characteristics who completed the study versus those who withdrew.

\section{Abbreviations}

BMI: body mass index; WC: waist circumference; HC: hip circumference; SBP: systolic blood pressure; DBP: diastolic blood pressure; MMSE: mini mental state examination; ADAS-Cog: Alzheimer's disease assessment scale-cognitive sub-scale.

\section{Authors' contributions}

$\mathrm{TM}$ and $\mathrm{AP}$ were responsible for data analysis and manuscript writing. NB was responsible for neuropsychological assessment. AF, EM and YF were responsible for enrollment, data collection and integrity of data. EM and SR were responsible for anthropometric and nutritional measurements SR revised the manuscript. All authors read and approved the final manuscript.

\section{Author details}

${ }^{1}$ Department of Medical and Surgical Science, Nutrition Unit, University Magna Grecia, Catanzaro, Italy. ${ }^{2}$ Department of Molecular and Clinical Medicine, University of Gothenburg, Gothenburg, Sweden. ${ }^{3}$ Neurology Unit, S. Giovanni di Dio Hospital, Crotone, Italy. ${ }^{4}$ Department of Clinical and Experimental Medicine, Nutrition Unit, University Magna Grecia, Viale S. Venuta, 88100 Catanzaro, Italy.

\section{Acknowledgements}

We would like to thanks Opipari and Torchia Companies for providing the extravirgin $\mathrm{OO}$ to all participants. In addition, we thanks the professor Antonio Procopio and Manuela Oliverio of the University Magna Grecia in Catanzaro for the chemical characterization of the $\mathrm{OO}$.

\section{Competing interests}

The authors declare that they have no competing interests.

Availability of data and materials

All data generated or analysed during this study are included in this published article.

Consent for publication

Not applicable. 


\section{Ethics approval and consent to participate}

The protocol was approved by the local ethics committee at the "Mater Domini" University Hospital in Catanzaro, Italy (Projects Codes 2011.48).

\section{Funding}

This study was supported by a Grant from the Italian Ministry of Health (GR 2009-1567179).

\section{Publisher's Note}

Springer Nature remains neutral with regard to jurisdictional claims in published maps and institutional affiliations.

Received: 31 August 2017 Accepted: 11 January 2018

Published online: 19 January 2018

\section{References}

1. Reitz C, Brayne C, Mayeux R. Medscape. Epidemiology of Alzheimer disease. Nat Rev Neurol. 2011;7:137-52.

2. Martinez-Lapiscina EH, Clavero P, Toledo E, Estruch R, Salas-Salvado J, San Julian B, Sanchez-Tainta A, Ros E, Valls-Pedret C, Martinez-Gonzalez MA. Mediterranean diet improves cognition: the predimed-navarra randomised trial. J Neurol Neurosurg Psychiatry. 2013;84:1318-25.

3. Zbeida M, Goldsmith R, Shimony T, Vardi H, Naggan L, Shahar DR. Mediterranean diet and functional indicators among older adults in non-Mediterranean and Mediterranean countries. J Nutr Health Aging 2014:18:411-8.

4. Katsiardanis K, Diamantaras AA, Dessypris N, Michelakos T, Anastasiou A Katsiardani KP, Kanavidis P, Papadopoulos FC, Stefanadis C, Panagiotakos DB, et al. Cognitive impairment and dietary habits among elders: the Velestino study. J Med Food. 2013;16:343-50

5. Chan R, Chan D, Woo J. A cross sectional study to examine the association between dietary patterns and cognitive impairment in older Chinese people in Hong Kong. J. Nutr. Health Aging. 2013;17:757-65.

6. Solfrizzi V, Colacicco AM, D'Introno A, Capurso C, Torres F, Rizzo C, et al. Dietary intake of unsaturated fatty acids and age-related cognitive decline: a 8.5-year follow-up of the Italian longitudinal study on aging. Neurobiol Aging. 2006;27:1694-704.

7. Lourida I, Soni M, Thompson-Coon J, Purandare N, Lang IA, Ukoumunne OC, Llewellyn DJ. Mediterranean diet, cognitive function and dementia: a systematic review. Epidemiology. 2013;24:479-89.

8. Aridi YS, Walker JL, Wright ORL. The association between the Mediterranean dietary pattern and cognitive health: a systematic review. Nutrients. 2017;9(7):674

9. Donini LM, Savina C, Cannella C. Eating habits and appetite control in the elderly: the anorexia of aging. Int Psychogeriatr. 2003;15:73-87.

10. Salas-Salvadó J, Bulló M, Babio N, Martínez-González MÁ, Ibarrola-Jurado N, Basora J, Estruch R, Covas MI, Corella D, Arós F, Ruiz-Gutiérrez V, Ros E, PREDIMED Study Investigators. Reduction in the incidence of type 2 diabetes with the Mediterranean diet: results of the PREDIMED-Reus nutrition intervention randomized trial. Diabetes Care. 2011;34:14-9.

11. Psaltopoulou T, Kyrozis A, Stathopoulos P, Trichopoulos D, Vassilopoulos D, Trichopoulou A. Diet, physical activity and cognitive impairment among elders: the EPIC-Greece cohort (European Prospective Investigation into Cancer and Nutrition). Public Health Nutr. 2008;11:1054-62.

12. Mazza E, Fava A, Ferro Y, Moraca M, Rotundo S, Colica C, Provenzano F, Terracciano R, Greco M, Foti D, Gulletta E, Russo D, Bosco D, Pujia A, Montalcini T. Impact of legumes and plant proteins consumption on cognitive performances in the elderly. J Transl Med. 2017;15:109.

13. Folstein MF, Folstein SE, McHugh PR. "Mini-mental state" a practical method for grading the cognitive state of patients for the clinician. J Psychiatr Res. 1995;12:189-98.

14. Plassman BL, Langa KM, Fisher GG, Heeringa SG, Weir DR, Ofstedal MB, Burke JR, Hurd MD, Potter GG, Rodgers WL, Steffens DC, McArdle JJ, Willis RJ, Wallace RB. Prevalence of cognitive impairment without dementia in the United States. Ann Intern Med. 2008;148:427-34.
15. Diniz BS, Yassuda MS, Nunes PV, Radanovic M, Forlenza OV. Mini-mental state examination performance in mild cognitive impairment subtypes. Int Psychogeriatr. 2007;19:647-56.

16. Bianchetti A, Scala V, Cipriani G, Trabucchi M. The Severe Mini Mental State Examination (SMMSE): validation of the Italian Version. Res Pract Alz Dis: Severe Dementia. 2003:8:39-45.

17. Rosen WG, Mohs RC, Davis KL. A new rating scale for Alzheimer's disease. Am J Psychiatry. 1984;141:1356-64.

18. Steenland K, Zhao L, Goldstein F, Cellar J, Lah J. Biomarkers for predicting cognitive decline in those with normal cognition. J Alzheimers Dis. 2014:40:587-94.

19. Loy C, Schneider L. Galantamine for Alzheimer's disease and mild cognitive impairment. Cochrane Database Syst Rev. 2006;1:CD001747.

20. World Medical Association. Declaration of Helsinki. JAMA 2013;310:2191-4

21. Steer RA, Beck AT, Brown G. Sex differences on the revised Beck Depression Inventory for outpatients with affective disorders. J Pers Assess. 1989:53:693-702.

22. Beck AT, Steer RA, Brown GK. Manual for the Beck Depression Inventory-II. San Antonio: Psychological Corporation; 1996.

23. Grober E, Hall C, McGinn M, Nicholls T, Stanford S, Ehrlich A, et al. Neuropsychological strategies for detecting early dementia. J Int Neuropsychol Soc. 2008;14:130-42.

24. Heun R, Papassotiropoulos A, Jennssen F. The validity of psychometric instruments for detection of dementia in the elderly general population. Int J Geriatr Psychiatry. 1998;13:368-80.

25. Laws KR, Duncan A, Gale TM. 'Normal' semantic-phonemic fluency discrepancy in Alzheimer's disease? A meta-analytic study. Cortex. 2010:46:595-601.

26. Katz S, Ford AB, Moskowitz RW, Jackson BA, Jaffe MW. Studies of illness in the aged: the index of ADL: A standardized measure of biological and psychosocial function. JAMA. 1963;185:914-9.

27. Graf C. The Lawton instrumental activities of daily living scale. AJN. 2008; 108(4):52-62.

28. Montalcini T, Gorgone G, Gazzaruso C, Sesti G, Perticone F, Pujia A. Carotid atherosclerosis associated to metabolic syndrome but not BMI in healthy menopausal women. Diabetes Res Clin Pract. 2007;76:378-82.

29. Ferro Y, Carè I, Mazza E, Provenzano F, Colica C, Torti C, Romeo S, Pujia A, Montalcini T. Protein and vitamin B6 intake are associated with liver steatosis assessed by transient elastography, especially in obese individuals. Clin Mol Hepatol. 2017;23:249.

30. Alberti-Fidanza A, Fidanza F. Mediterranean adequacy index of Italian diets. Public Health Nutr. 2004;7(7):937-41

31. Montalcini T, Gorgone G, Federico D, Ceravolo R, Emanuele V, Sesti G, Perticone F, Pujia A. Association of LDL cholesterol with carotid atherosclerosis in menopausal women affected by the metabolic syndrome. Nutr Metab Cardiovasc Dis. 2005;15:368-72.

32. Kraemer HC. Reporting the size of effects in research studies to facilitate assessment of practical or clinical significance. Psychoneuroendocrinology. 1992;17:527-36.

33. Valls-Pedret C, Lamuela-Raventós RM, Medina-Remón A, et al. Polyphenol-rich foods in the Mediterranean diet are associated with better cognitive function in elderly subjects at high cardiovascular risk. J Alzheimers Dis. 2012;29:773-82.

34. Violi F, Loffredo L, Pignatelli P, Angelico F, Bartimoccia S, Nocella C, Cangemi R, Petruccioli A, Monticolo R, Pastori D, Carnevale R. Extra virgin olive oil use is associated with improved post-prandial blood glucose and LDL cholesterol in healthy subjects. Nutr Diabetes. 2015;5:e172.

35. Yates KF, Sweat V, Yau PL, Turchiano MM, Convit A. Impact of metabolic syndrome on cognition and brain: a selected review of the literature. Arterioscler Thromb Vasc Biol. 2012;32:2060-7.

36. Biessels GJ, Staekenborg S, Brunner E, Brayne C, Scheltens P. Risk of dementia in diabetes mellitus: a systematic review. Lancet Neurol. 2006:5:64-74

37. US Food and Drug Administration. Press Release P04-100. November 1, 2004. http://www.fda.gov/bbs/topics/news/2004/NEW01129.htlm. Accessed 28 Oct 2006.

38. Amieva H, Le Goff M, Millet X, et al. Prodromal Alzheimer's disease: successive emergence of the clinical symptoms. Ann Neurol. 2008;64:492-8. 
39. García A, Ruiz-Méndez MV, Romero Barranco C, Brenes M. Effect of refining on the phenolic composition of crude olive oils. J Am Oil Chem Soc. 2006:83:159-64.

40. Reaven PD, Witztum JL. Oxidized low density lipoproteins in atherogenesis: role of dietary modification. Annu Rev Nutr. 1996;16:51-71.

41. Lee C, Barnett J, Reaven PD. Liposomes enriched in oleic acid are less susceptible to oxidation and have less proinflammatory activity when exposed to oxidizing conditions. J Lipid Res. 1998;39:1239-47.

42. Bulotta S, Celano M, Lepore SM, Montalcini T, Pujia A, Russo D. Beneficial effects of the olive oil phenolic components oleuropein and hydroxytyrosol: focus on protection against cardiovascular and metabolic diseases. J Transl Med. 2014;3(12):219.

43. Fernstrom JD, Wurtman RJ. Brain serotonin content: increase following ingestion of carbohydrate diet. Science. 1971;174:1023-5.

44. Markus CR, Panhuysen G, Tuiten A, Koppeschaar H, Fekkes D, Peters ML. Does carbohydrate-rich, protein-poor food prevent a deterioration of mood and cognitive performance of stress-prone subjects when subjected to a stressful task? Appetite. 1998:31:49-65.
45. Leone A, Battezzati A, De Amicis R, De Carlo G, Bertoli S. Trends of adherence to the Mediterranean Dietary pattern in Northern Italy from 2010 to 2016. Nutrients. 2017;9(7):E734. https://doi.org/10.3390/nu9070734.

46. Canevelli M, Adali N, Kelaiditi E, Cantet C, Ousset PJ, Cesari M, ICTUS/DSA Group. Effects of Gingko biloba supplementation in Alzheimer's disease patients receiving cholinesterase inhibitors: data from the ICTUS study. Phytomedicine. 2014;21:888-92.

47. Oxford CEBM. http://www.cebm.net/levels_of_evidence.asp.

48. Fewtrell M, Kennedy K, Singhal A, Martin RM, Ness A, Hadders-Algra $M$, Koletzko B, Lucas A. How much loss to follow-up is acceptable in long-term randomised trials and prospective studies? Arch Dis Child. 2008;93:458-61.

\section{Submit your next manuscript to BioMed Central and we will help you at every step:}

- We accept pre-submission inquiries

- Our selector tool helps you to find the most relevant journal

- We provide round the clock customer support

- Convenient online submission

- Thorough peer review

- Inclusion in PubMed and all major indexing services

- Maximum visibility for your research

Submit your manuscript at www.biomedcentral com/submit 